\title{
KARAKTERISTIK DAKWAH KHULAFA AL-RASYIDIN
}

\section{Muhammad Patri Arifin}

Institut Agama Islam Negeri Palu

Email: muhammadpatriar@gmail.com

\section{Abstract:}

After the Prophet Muhammad passed away, Islamic propagation was carried out the Prophet's companions, such as Abu Bakr, Umar, Uthman and Ali, known as Khulafa' Rashidin (rightly guided caliphs). Their mission of da'wah was never deviated from the teachings of the Prophet, but carried out with different practices. Abu Bakr, for example, paid special attention to the spread of true way of life. Because of his efforts, most Arabs converted to Islam. After Abu Bakr's chalipate, Umar managed Islamic government and effective administration. At Uthman's period, he extinguished rebellion that occurred in some areas, and expanded the reign of Islam that halted in the caliphate of Umar. In addition, Uthman's spectacular effort is the collection and writing of the Quran, later known as the Ottoman Manuscripts. In his period, Ali applied the principle of equality among Muslims, while a political aspect, he was very decisive in supervising his staffs and officials (local authorities).

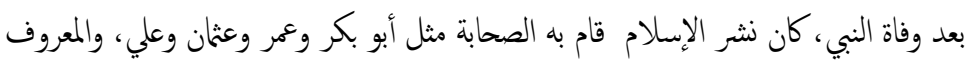

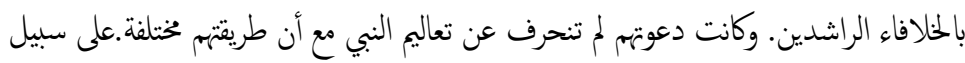

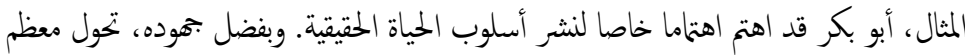

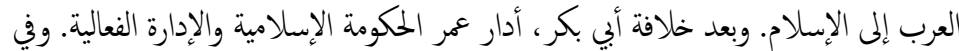

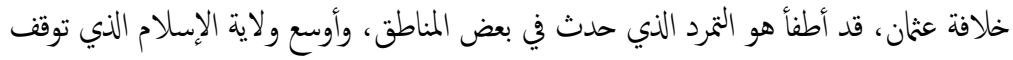

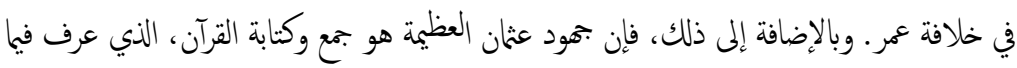

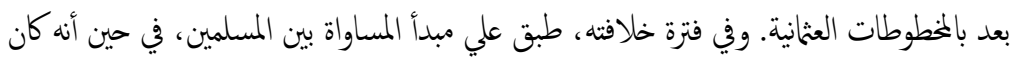

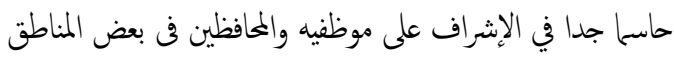

Kata Kunci: karakteristik, dakwah, khulafa al-rasyidin. 
Muhammad Patri Arifin, Karakteristik Dakwah Khulafaurrasyidin

\section{A. Pendahuluan}

Ketika Allah swt. memilih Muhammad sebagai Nabi-Nya untuk memangku tugas risalah, beliau dibaiat di Gua Hira, diperlakukan di atas pengawasan-Nya dididik yang sebaik-baiknya dan dibekali dengan yang membuatnya mampu memikul amanat penyampaian risalah dan membangun umat yang baik yang dipersiapkan untuk umat manusia seluruhnya. ${ }^{1}$

Islam adalah agama dakwah ${ }^{2}$ hukumnya fardhu kifayah atas seluruh umat muslimin. ${ }^{3}$ Sepeninggal Nabi Muhammad saw. dakwah Islam dilanjutkan oleh sahabat-sahabatnya. Sebagaimana Nabi Muhammad saw. yang melakukan dakwah Islam dalam bentuk

${ }^{1}$ Berkaitan dengan uraian tersebut selanjutnya Allah swt. berfirman:

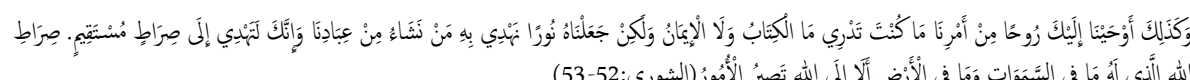

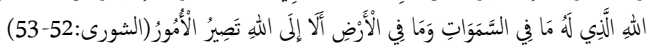

Terjemahnya:

Dan demikianlah Kami wahyukan kepadamu wahyu (Alqurān) dengan perintah Kami. Sebelumnya kamu tidaklah mengetahui apakah Al Kitab (Alqurān) dan tidak pula mengetahui apakah iman itu, tetapi Kami menjadikan Alqurān itu cahaya, yang Kami tunjuki dengan dia siapa yang Kami kehendaki di antara hamba-hamba Kami. Dan sesungguhnya kamu benar-benar memberi petunjuk kepada jalan yang lurus. (Yaitu) jalan Allah yang kepunyaan-Nya segala apa yang ada di langit dan apa yang ada di bumi. Ingatlah, bahwa kepada Allah-lah kembali semua urusan. (QS. Asy-Syuura: 52-53). Lihat Hasan Baidai, Kunci Sukses Petugas dakwah (Cet. I; Yogyakarta: Bina Usaha, 1984), h. 116.

${ }^{2}$ Agama dakwah diartikan agama yang selalu mendorong pemeluknya untuk senantiasa aktif melakukan kegiatan dakwah. Kemajuan dan kemunduran umat Islam, sangat berkaitan erat dengan kegiatan dakwah yang dilakukannya. Karena itu Alqurān menyebut kegiatan dakwah dengan ahsanul qaula (ucapan yang paling baik). Lihat Didin Hafiduddin, Dakwah Aktual (Cet. I; Jakarta: Gema Insani Press, 1998), h. 76.

${ }^{3}$ Lihat Abu Zahrah, Dakwah Islamiyah (Cet. I; Bandung: Remaja Rosdakarya, 1994), h. 142. 


\section{$\Delta$-nis $3 \exists \bar{\lambda} /$, Volume 13 Nomor 1, Januari-Juni 2017: 165-182}

peperangan (terhadap kaum muslimin), sahabat-sahabat pun relatif menempuh cara itu namun dengan praktek operasional yang berbeda.

Keempat khalifah utama yakni Abu Bakar, Umar bin Kahttab, Usman bin Affan dan Ali bin Abi Thalib dengan tegas mengikuti cara-cara beliau. ${ }^{4}$ Masa mereka merupakan golden age Islam, ketika itu hukum dan agama Islam, syariat sepenuhnya berkembang dan diimplementasikan secara sempurna. Mereka adalah para penguasa ideal yang membimbing umat (para pengikut Rasulullah saw.) di atas jalan yang benar dan telah melaksanakan tugas dengan penuh keimanan. Karena alasan ini mereka dikenal sebagai Khulafa al-Rasyidin. ${ }^{5}$

Keempat sahabat beliau tersebut memperlihatkan laga dakwahnya pada masa kekhalifahannya masing-masing. Berpijak dari uraian latar belakang tersebut, maka penulis akan membahas bagaimana karakteristik dakwah Khulafa al-Rasyidin tersebut.

\section{B. Pembahasan}

\section{Abu Bakar al-Siddiq}

Abu Bakar al-Siddiq, ${ }^{6}$ kaum muslimin memanggilnya khalifah Allah, tetapi dia keberatan terhadap julukan itu dan berkata bahwa dia

${ }^{4}$ Madjid Ali Khan, Sisi Hidup Para Khalifah Saleh (Cet. I; Surabaya: Risalah Gusti, 2000), h. 1

${ }^{5}$ Khulafaur-Rasyidin diartikan para khlaifah penunjuk jalan kebenaran. Ada sejumlah ayat di dalam Alquran yakni (QS. 2 : 30; QS. 7 : 10; QS. 69 : 74, 129; QS. 38: 26; QS. 35 : 39) di mana institusi kekhalifahan telah didefenisikan sejurus atau dengan cara menjelaskan secara langsung terhadap Khulafaur-Rasyidin, maka tidak disebut di sini. Lihat ibid., h. $2-3$.

${ }^{6}$ Lihat Mahbub Djunaidi, Seratus Tokoh yang Paling Berpengaruh dalam Sejarah (Cet. I; Jakarta: Pustaka Jaya, 1982), h. 9. 
hanyalah "kahlifah dari pesuruh Allah". Oleh karena itu julukan "Khalifah Rasulullah" telah digunakan dengan namanya. ${ }^{7}$

Abu Bakar al-Siddiq orang pertama yang menyambut dakwah Rasulullah untuk memeluk Islam. setiap kali Rasulullah menyebut nama Abu Bakar, maka dia akan menyatakan penghormatannya yang tinggi. Rasulullah seringkali mengungkapkan Abu Bakar secara spontanitas menerima Islam tanpa ragu-ragu. ${ }^{8} \mathrm{Di}$ dalam menjalankan dakwahnya, ia relatif masih menempuh cara-cara perang yang kemudian diikuti dengan amar ma'ruf nahi mungkar secara hikmah.

Thomas W. Arnold menulis, setelah wafatnya Rasulullah saw. tentara (pasukan perang) yang telah dipersiapkan oleh Rasulullah untuk memasuki Syiria dilanjutkan oleh Abu Bakar, kendati mendapat sanggahan beberapa sahabat besar lainnya dengan alasan, masih kacaunya keadaan di Arab sendiri. Abu Bakar menjawab sanggahan itu dengan kata-kata: "Aku tidak akan melanggar setiap perintah yang diberikan oleh Rasulullah saw. Madinah boleh menjadi sarang binatang buas, namun pasukan tentara wajib melaksanakan keinginan Rasulullah. ${ }^{9}$

Dengan peperangan ${ }^{10}$ yang dilakukan Abu Bakar itu memicu watak dan semangat nasionalisme wakil-wakil representatif Arab untuk menggabungkan diri ke dalam tentara Islam (pasukan penyerbu), hal mana menambah licin jalan kemenangan. Keturutsertaannya dalam 31.

${ }^{7}$ Syekh Mu'inuddin Nadawi, Khulafaur Rasyidin (Cet. III; India: Azangarh, 1994),h.

${ }^{8}$ Lihat Afzal Iqbal, Diplomasi Islam (Cet. I; Jakarta: Pustaka al-Kautsar, 2000), h. 125.

${ }^{9}$ Lihat Thomas W. Arnold, The Preaching of Islam (Cet. IV; Lahore Ashaf Printing Press, 1979), h. 44.

${ }^{10}$ Peperangan yang dimaksudkan adalah perang Qadisiyah $(14 \mathrm{H})$ 


\section{$\Delta$-nis $3 \exists \bar{\lambda}$ H, Volume 13 Nomor 1, Januari-Juni 2017: 165-182}

peperangan ini, di mana setelah kemenangan diperoleh tentara Islam, banyak suku-suku Badui Kristen yang hanyut terbawa arus dengan peperangan ini, yang berabad-abad menganut agama Kristen ini, meninggalkannya untuk berbalik menganut agama Islam. Di antara mereka ialah Bani Ghasasinah yang mendiami padang pasir timur Palestina dan sebelah selatan Syiria. Mereka inilah yang dijuluki raja-raja pada zaman jahiliyah dan binatang-bintang pada masa Islam.

Abu Bakar secara ke dalam (internal kaum msulimin) untuk menegakkan ajaran-ajaran Islam, relatif tetap menggunakan jargon perang sebagai metode dakwah. Ahmad Syalabi menulis bahwa sesudah Rasulullah wafat, agama Islam menghadapi krisis dengan adanya golongan yang murtad, ${ }^{11}$ golongan yang mengaku diri sebagai nabi dan golongan yang enggan membayar zakat. Dalam hal ini di antara kaum muslimin terjadi pro-kontra dalam menyikapinya. Ada yang berpendapat tak ada alasann untuk memerangi mereka dan ada pula yang berpendapat wajiob memerangi mereka dalam kesulitan yang memuncak ini. ${ }^{12}$ Tampak kebesaran dan ketabahan hati Abu Bakar untuk menyeru mereka kembali kepada kebenaran, di mana yang tetap enggan beliau perangi, demi memperjuangkan kemuliaan agama Allah. ${ }^{13}$

Penyebaran Islam oleh khalifah Abu Bakar manaruh perhatian khusus pada penyebaran jalan hidup yang benar. Karena usahanya

\footnotetext{
${ }^{11}$ Berbalik ke belakang; berbalik menjadi kafir; membuang iman; berganti menjadi ingkar. Lihat Depdikbud RI., Kamus Besar Bahasa Indonesia (Cet. II; Jakarta: Balai Pustaka, 1989), h. 601.

${ }^{12}$ Kaum Muslimin hampir pecah dan saling memusuhi.

${ }^{13}$ Lihat Ahmad Syalabiy, Mansu'at al-Tarikh wa al-Hadarat al-Islamiyah (Cet. V; Mesir: Maktabah al-Nahdhah al-Misriyyah, 1979), h. 137.
} 
seluruh Arab sekali lagi dan untuk selamanya masuk kembali ke dalam Islam.

Ia telah memberi instruksi-instruksi yang tegas kepada semua tentaranya, untuk pertama kali, menyeru musuh-musuh Islam. Ajakan pada Islam yang biasanya diberikan selama tiga hari sebelum memulai suatu pertempuran. Sejumlah suku di Iraq dan tempat-tempat lain menerima Islam tanpa suatu pertempuran ketika Khalid r.a. dan para komandan lainnya menyebarkan Islam. sekali waktu seorang pendeta Kristen dari Hira menerima Islam setelah melihat tingkah laku yang baik dari kaum muslimin. ${ }^{14}$

Abu Bakar adalah sosok langka yang mampu menggabungkan antara kelemah-lembutan dan ketegasan pada saat yang bersamaan. Siapa saja orang yang pernah melakukan pemberontakan kepadanya lalu datang ke hadapannya untuk mengakui kesalahannya, maka dia akan dengan lapang dada memaafkannya. Qara' bin habirah, Amir bin Mahdi dan Asy'ats bin Qays, adalah contoh orang-orang yang diberi maaf oleh kahlifah Abu Bakar dan contoh dari kebijakan khalifah. ${ }^{15}$

${ }^{14}$ Lihat Madjid Ali Khan, Sisi Hidup...., h. 66.

${ }^{15}$ Satu tindakan yang demikian tegas dan fleksibel dari sosok sederhana itulah yang membuat Islam mampu hidup di tengah tantangan yang demikian serius dari berbagai pihak yang mengancam wujud dan keberadaannya. Dengan misi yang demiliki, pandangannya yang jauh ke depan dan kebijakannnya, Abu Bakar mampu mempersepsikan bahwa sebuah bahaya besar telah mengancam dari sekitar Madinah dan kemudian ke berbagai negeri, di saat koleganya menganggap hal itu sesuatu yang tidak mesti mendapat perhatian besar. dan berkat kekokohannya serta usahanya yang demikian keras untuk tidak berkompromi dan memberikan konsesi kepada musuh-musuh, maka Islam tetap berdiri kokoh dan jaya. Abu Bakar bukan saja mampu mempertahankan batasbatas geografis, namun sekaligus juga mampu mempertahankan batas spiritual Islam. lihat Afzal Iqbal, Diplomasi Islam..., h. 138. 


\section{$\Delta L$-nis $\mathrm{H} \exists \bar{\Delta}$ H, Volume 13 Nomor 1, Januari-Juni 2017: 165-182}

Suksesi berikutnya Abu Bakar adalah sahabat Nabi yang merupakan penghafal Alquran dan berusaha mengumpulkan ayat-ayat Alquran itu menjadi satu kitab sesuai dengan apa yang didiktekan Rasulullah saw. kepada dirinya. ${ }^{16}$ Kumpulan dari ayat-ayat itu diserahkan kepada Abu Bakar yang kemudian diberi nama mushaf. Sepeninggal Abu Bakar r.a. yang wafat hari Selasa, 22 Jumadil Akhir 13 H. (23 Agustus $634 \mathrm{M})$, yang melanjutkan kegiatan pemerintahan dan dakwahnya adalah Umar bin Kahttab.

Dari data tersebut menunjukkan bahwa Abu Bakar dalam mendakwakan Islam, demikian kukuhnya mengikuti jejak langkah Rasulullah sehingga sama saja tegasnya dalam menghadapi umat, baik kaum kafir maupun kaum muslim.

\section{Umar Ibn Khattab}

Umar ibn Khattab mengikuti jejak pendahulunya. Begitu dikukuhkan sebagai khalifah yang kedua dia terus naik mimbar masjid dan berpidato ${ }^{17}$ kepada mereka yang hadir. Dia menyatakan antara lain bahwa bangsa Arab ibarat seekor unta yang ditarik dengan gelang pada

${ }^{16}$ Ibid., h. 139.

${ }^{17}$ Isi pidatonya: "Wahai kaum muslimin, bagaimana sikap kalian seandainya saya cenderung kepada kesenangan duniawi? Sesungguhnya saya takut kalau (satu waktu) saya berbuat salah tetapi dari kalian tidak ada seorang pun menentangku karena hormat kalian kepadaku. Maka (permintaan saya) kalau saya berbuat baik, bantulah saya tetapi kalau saya berbuat jelek harap kalian perbaiki”. Pada ketika itu bangun seorang di antara hadirin dan berkata: "Demi Allah, wahai Amir al-Mukminin, kalau kami melihat anda membengkok, maka kami lempangkan kembali dengan pedang-pedang kami”. Dengan tenang Umar menjawab: "Semoga Allah sayang kepada kalian, dan segala puji bagi Allah bahwa di antara kalian terdapat orang yang berani mengoreksi Umar dengan pedangnya." Lihat Munawir Sjadzali, Islam dan Tata Negara: Ajaran, Sejarah dan Pemikiran (Edisi V; Jakarta: UI-Press, 1993), h. 28 - 29. 
hidungnya. Kemanapun ditarik ia akan ikut. Tetapi dalam mengikuti Umar dia meminta hendaknya mereka melihat ke mana mereka akan dihela. Sementara itu dia menjanjikan akan memimpin mereka pada jalan yang benar.

Islamnya Umar bin Kahttab ${ }^{18}$ adalah suatu kemenangan, hijrahnya adalah suatu rahmat. Demikianlah sebuah riwayat Asir dari Abdullah bin Mas'ud. ${ }^{19}$ Dengan riwayat ini mengisyaratkan betapa besar pengaruh Umar terhadap perkembangan dakwah Islam.

Sebagaimana halnya Abu Bakar yang melanjutkan peperangan yang tidak sempat dilakukan oleh Rasulullah (karena wafat), namun telah dipersiapkannya, Umar juga melanjutkan peperangan yang tidak sempat dilakukan Abu Bakar karena wafat, namun telah dirintisnya. Dalam masa kekhalifhannya, ia melakukan ekspansi Islam ke Persia, Romawi, dan Mesir.

Dalam ekspansi Islam yang dilakukan Umar itu menimbulkan tiga kondisi nyata, yaitu pertama, banyaknya penganut Islam baru akibat derasnya arus penduduk yang berbondong-bondong masuk Islam. Kedua, terdapatnya penduduk /warga setempat (pada daerah-daerah yang baru ditaklukkan) yang beragama non-Islam atau masih menganut kepercayaan lama (Kristen). Dan ketiga, bertambah luasnya wilayah pemerintahan Islam yang memerlukan pengelolaan dan penanganan administrasi yang efektif.

${ }^{18}$ Umar bin Khattab menjadi Khalifah selama 11 tahun (13-24 H. / $634-644$ M.).

${ }^{19}$ Lihat Abu Zahrah, Khatam al-Nabiyyin (Cet. I; t.t.: Maktabah Fikriyah, t.th.), h. 448. 


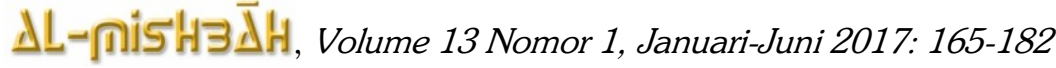

Untuk yang pertama, Umar menyusun ketentuan-ketantuan khusus mengenai materi pendidikan dan metode pengajaran agama, baik mengenai pokok-pokok iman maupun soal-soal ibadah. Dalam hal ini diangkat dan ditunjuklah guru-guru ${ }^{20}$ untuk setiap daerah yang bertugas mengajarkan kepada penduduk tentang isi Alqurān dan soal-soal yang berhubungan dengan kepercayaan lama (kekristenan ) mereka. Ia memerintahkan pula kepada pembesar pemerintahan untuk mengawasi apakah penduduk (tua dan muda) selalu mengikuti atau melaksanakan, shalat jamaah terutama shalat Jum'at dan ibadah pada bulan Ramadhan.

Dalam aspek penegakan hukum atau syari'ah, $\operatorname{Umar}^{21}$ misalnya menolak memberikan zakat kepada kaum mu'alla ${ }^{22}$ dengan alasannya: ${ }^{23}$ bahwa sesungguhnya Allah telah memuliakan/ meninggikan agama Islam). Begitu pula tidak menjatuhkan sanksi potong tangan bagi pencuri karena ketiadaan makanan akibat musim paceklik. ${ }^{24}$

Untuk yang kedua, Umar menerapkan kebijaksanaan toleransi (antar umat beragama) dalam hal ini, Umar misalnya melarang adanya tekanan kekerasan apabila mereka ternyata tidak rela meninggalkan kepercayaan mereka semula dan menjamin mereka melakukan ibadah, namun sebaliknya, mereka tidak diperkenankan melarang anggotaanggota mereka yang ingin masuk Islam dan tidak pula membaptis anak-

\footnotetext{
${ }^{20}$ Guru-guru yang diangkat dan ditunjuk Umar termasuk pembesar/ pejabat pemerintahh seperti bendaharawan Kota futah. Lihat Thomas W. Arnold, The Preching..., h. 45 .

${ }^{21}$ Lihat ibid.

${ }^{22}$ Muallaf ialah orang yang baru masuk Islam (Depdikbud), Kamus..., h. 593.

${ }^{23}$ Al-Khudariy Bek, Tarikh Tasyri' al-Islamiy (Mesir: Daar al-Fikr, 1968), h. 19.

${ }^{24}$ Sikap (kebijaksanaan) Umar ini menjadi referensi ijtihad bagi ulama/ cendikiawan Islam kontemporer.
} 
Muhammad Patri Arifin, Karakteristik Dakwah Khulafaurrasyidin

anak mereka yang sudah masuk Islam. ${ }^{25}$ Tidak ada paksaan bagi mereka mengenai soal-soal yang berhubungan dengan keyakinan mereka, dan tidak seorang pun di antara mereka yang akan dianiyah. ${ }^{26}$ Akan tetapi dalam pada ini, demi kontribusi mereka kepada khilafah Islam, Umar menetapkan sumbangan wajib mereka dengan 5 Dinar bagi golongan kaya, 4 Dinar bagi golongan menengah dan 3 Dinar bagi rakyat biasa/ golongan bawah. ${ }^{27}$

Dalam aspek muamalah, diriwayatkan bahwa Umar antara lain pernah memerintahkan agar menyumbang uang dan makanan dari Baitul Mal untuk para penderita sakit lepra di kalangan orang-orang kristen, bahkan dalam wasiatnya yang terakhir, di mana ia menunjuk penggantinya sebagai khalifah, ia menyinggung masalah $Z_{i m m i^{8}}$ agar mereka itu tetap menikmati perlindungan Tuhan dan Rasulullah, juga agar dia menepati perjanjian dengan mereka dan janganlah ia membebani mereka dengan beban-beban yang tidak sanggup mereka pikul. ${ }^{29}$

Dan untuk yang ketiga, Umar menyusun dewan-dewan, mendirikan baitul mal, menempa mata uang, membentuk angkatan bersenjata (tentara) untuk menjaga / melindungi tapal batas mengangkat

${ }^{25}$ Lihat Thomas W. Arnold, The Preaching of Islam..

${ }^{26}$ Lihat ibid., h. 52.

${ }^{27}$ Lihat ibid.

${ }^{28}$ Kaum atau $\mathrm{Ahl}$ al-Zimmi adalah penduduk dari satu negeri Islam yang tidak beragama Islam tetapi tunduk kepada pemerintahan Islam.

${ }^{29}$ Lihat Thomas W. Arnold, The Preaching... 
hakim, mengatur perjalanan pos, menciptakan penanggalan tahun Hijriyyah dan sebagainya. ${ }^{30}$

Berdasarkan data tersebut, memperlihatkan bagaimana Umar merencanakan dakwah dengan begitu optimal, yang meliputi pembinaan intern umat / penduduk muslim, antara umat beragama dan kenegaraan. Dengan ini, Michael Hart menempatkan Umar sebagai tokoh rangking nomor 51 dunia. ${ }^{31}$

\section{Usman Ibn'Affan}

Usman ibn 'Affan ${ }^{32}$ termasuk juga salah seorang di antara alsabiquna al-awwalun. Ia dikenal sebagai seorang kaya yang dermawan yang banyak membantu pengembangan risalah Muhammad. Ia menikahi 2 puteri Rasulullah dan melakukan hijrah 2 kali, sehingga beliau dijuluki zunnurayn wa al-hijratayn.

Kedermawanan Utsman bin Affan pada zaman awal Islam (masa Nabi), terlihat pada waktu Nabi saw. mengerahkan jaysy al-usrah, ${ }^{33} \mathrm{di}$ mana Utsman mendermakan 950 ekor unta, 59 ekor kuda, dan 1000 dinar untuk keperluan / bekal lasykar Islam. Bahkan pada peristiwaperistiwa sebelum itu pula, Utsman banyak menyumbangkan hartanya untuk kemenangan Islam. ${ }^{34}$

${ }^{30}$ Lihat al-Tabariy, Tarikh al-Tabariy Juz III (t.tp: al-Ma'arif, t.th.), h. 277.

${ }^{31}$ Mahbub Djunaidi, Seratus Tokoh...

${ }^{32}$ Utsman menjadi Khalifah selama 12 tahun (24 - 36 H. / $\left.644-656 \mathrm{M}\right)$.

${ }^{33}$ Bala tentara yang dikerahkan pada waktu Perang Tabuk, di mana pada waktu itu pasukan Islam dilanda kesulitan mengenai perlengakapan dan bekal perang.

${ }^{34}$ Lihat hassan Ibrahim hassan, Islamic History and Culture from 632 - 1968, diterjemahkan oleh Djahdan Human dengan judul Sejarah dan Kebudayaan Islam (Cet. I; Yogyakarta: Kota Kembang, 1990), h. 57. 
Adapun upaya besar (yang menonjol) yang dilakukan Utsman dalam rangka pengembangan Islam, ada 2 aspek yaitu (1) menumpas pemberontakan dan pendurhakaan yang terjadi di beberapa daerah pada masa kekhalifahan Umar dan (2) memperluas kekuasaan Islam yang terhenti pada masa kekhalifahan Umar. ${ }^{35}$

Dan secara ke dalam (internal umat Islam), Usman begitu kukuh, sabar dan tabah dalam upaya menegakkan hukum-hukum Allah. Hal ini terlihat ketika menghadapi situasi gawat umat Islam (akibat pemberontakan) dan rencana pembunuhan atas dirinya, ia mengemukakan sabda Nabi saw.: Tidak dihalalkan darah seseorang muslim kecuali sebab tiga faktor, (1) orang yang murtad, (2) orang yang bersina setelah beristri atau bersuami, dan (3) orang yang merenggut nyawa orang lain tanpa alasan yang sah (menurut syara).$^{36}$ Demi Allah baik pada masa jahiliyah maupun pada masa Islam aku sama sekali, setelah Allah memberi hidayah kepadaku, aku tidak pernah berpikir hendak berganti agama, aku sama sekali tidak pernah berbuat zina dan aku tidak pernah merenggut nyawa orang lain tanpa hak yang sah. Kalau mereka membunuhku, maka sepeninggalku, mereka tidak akan bersembahyang jamaah lagi selama-lamanya dan tidak akan dapat berperang bahu-membahu melawan musuh. Ia menekankan agar kaum muslimin juga jangan saling membunuh dan saling berperang. Ketika didesak supaya mengumumkan perang melawan kaum pemberontak, Utsman menjawab Rasulullah saw. telah menyatakan janji, kepadaku dan

\footnotetext{
${ }^{35}$ Lihat Ahmad Syalabiy, Mausu'at al-tarikh...., h. 270.
}

${ }^{36}$ Lihat Thaha Husain, al-Fitnah al-Kubra, diterjemahkan oleh Moh. Tohir dengan judul Malapetaka Terbesar dalam Sejarah Islam (Cet. I; Jakarta: Pustaka Jaya, 1985), h. $305-309$. 


\section{$\Delta$-nis $3 \exists \bar{\lambda} /$, Volume 13 Nomor 1, Januari-Juni 2017: 165-182}

aku akan tetap bersabar memegang janji yang telah dinyatakan beliau itu sampai aku jatuh tersungkur di tempat di mana aku ditakdirkan harus mati. Demikianlah ia bertukar pikiran dan bercakap-cakap dengan beberapa orang sahabatnya dari satu soal ke soal yang lain hingga tiba saat kaum pemberontak menyerang dan membunuhnya. ${ }^{37}$

Selain itu, satu upaya besar (karya spektakuler) yang dilakukan Utsman (sebagai buah dari pengalamannya menjadi sekretaris sekaligus penasehat 2 khalifah pendahulunya, Abu Bakar dan Umar), sebagaimana yang sudah banyak diketahui umat teristimewa kalangan terpelajar Islam ialah pengumpulan dan penulisan Alquran, yang kemudian dikenal dengan mushaf utsmani.

\section{4. 'Ali Ibn Abi Thalib}

'Ali Ibn Abi Thalib' ${ }^{38}$ termasuk juga salah seorang di antara alsabiquna al-awwalun dari kalangan anak-anak. Ia memiliki ilmu yang banyak terutama ilmu rahasia ketuhanan dan persoalan keagamaan. Ia yang menjaga dan tidur ditempat tidur Rasulullah ketika hijrah ke Madinah bersama Abu Bakar. ${ }^{39}$

Ali bersama Abu bakar dan Umar (sehingga dikenal 3 tokoh) yang mengambil pengetahuan, budi pekerti, dan kebersihan jiwa dari Rasulullah. Ia pun dikenal sosok yang gagah berani di mana hampir seluruh peperangan yang dipimpin Rasulullah, ia selalu berada di barisan terdepan.

\footnotetext{
${ }^{37}$ Lihat ibid.

${ }^{38}$ Ali menjadi khalifah selama 7 tahun $(36-41 \mathrm{H} . / 656-661 \mathrm{M})$.

${ }^{39}$ Ensiklopedi Islam, Jilid I (Jakarta: Ikhtiar Baru, 1994), h. III.
} 
Adapun upaya dakwah yang dilakukan Ali pada masa kekhalifahannya, antara lain sebagaimana dikemukakan panjang-lebar oleh Taha Husain seperti berikut: Betapapun banyak persoalan gawat mengenai peperangan yang dihadapi Ali, namun semua itu tidak menghabiskan seluruh waktu dan kegiatan sehari-harinya di Kufah (untuk peperangan). Ia dapat membagi waktunya. Waktu untuk urusan perang, soal politik dan soal keagamaan. Ia tidak lalai terhadap kewajibannya sebagai pemimpin umat, dan tidak tenggelam pada kesedihannya betapapun beratnya. Dalam hal ini, ia tidak berbeda dengan khalifahkhalifah pendahulunya yang mengimami shalat jamaah, mengingatkan kaum muslimin agar tetap mematuhi ajaran-ajaran agama, dan mengajarkan kepada mereka tentang pengetahuan agama seluas-luasnya. Semua itu dilakukan kadang-kadang dari atas mimbar (khutbah) sambil berdiri dan duduk bersama mereka. Ia selalu duduk-duduk bersama kaum muslimin di dalam masjid, menanyakan kesukaran-kesukaran yang dihadapi tentang berbagai segi kehidupan, baik soal keagamaan maupun keduniaan. Ia benar-benar bertindak sebagai imam dan guru. ${ }^{40}$

Ali bergaul erat sekali dengan kaum muslimin, terutama pada saat kehidupan mereka sedang goncang. Ia berkeliling di tempat-tempat perdagangan sambil memperingatkan orang supaya tetap bertaqwa kepada Allah dan mengingatkan akan datangnya hari perhitungan kelak di akhirat. Ia langsung mengamat-amati mereka yang sedang berjual-beli, dengan sambil jalan ditempat perdagangan itu, ia mengeluarkan suara keras yang mengingatkan bertaqwalah kepada Allah, penuhilah timbangan dan takaran, dan jangan memalsukan daging. Bila ia melihat

${ }^{40}$ Lihat Taha Husain, al-Fitnah al-Kubra..., h. 514. 
seorang yang berbuat tidak semestinya, ia memberi peringatan keras dengan membentak dan kadang-kadang dengan cambuk pendeknya. ${ }^{41}$

Ali dengan memelihara diri dari kekuasaan, apabila ia hendak membeli sesuatu, ia mencari penjual yang tidak mengenalnya, dengan maksud jangan sampai sipenjual memberi keistimewaan kepadanya lantaran tahu bahwa dirinya seorang Amirul Mukminim. ${ }^{42}$

Ali pun sesudah melakukan shalat tahajjud dan amalan lainnya, setelah tidur sejenak, menjelang subuh, ia keluar masjid membangunkan orang-orang yang tidur di dalamnya dengan ucapan: Hai hamba Allah, shalat, shalat! Siang malam, ia mendorong kaum muslimin agar tidak segan-segan bertanya kepadanya mengenai soal-soal agama yang belum mereka pahami. ${ }^{43}$

Dalam soal hak asasi manusia, (khususnya dalam aspek persamaan harkat dan martabat), Ali menerapkan prinsip persamaan di antara sesama kaum muslimin. Hal itu tampak pada saat-saat membagikan harta dari Baitul Mal. Bahkan pada saat orang meminta sesuatu kepadanya, ia tetap berusaha menegakkan prinsip persamaan dalam memberi (tidak membedakan status sosial seseorang). ${ }^{44}$

${ }^{41}$ Lihat ibid., h.515. (Dari pengalamannya ia mengerti bahwa cambuk pendek seperti yang selalu dipegang Umar itu tidak lagi memberi peringatan kepada generasi belakangan. Meraka telah berkembang, bertingkah laku yang keras dan kasar serta banyak menyeleweng dari kebiasaan kaum muslimin zaman Umar. Karena itu, ia mengganti cambuk pendeknya dengan rotan, sebab ia berpendapat, rotan dirasa lebih sakit dari pada cambuk pendek. Kemudian ia tahu, bahwa rotan tidak ditakuti lagi, ia berkata kepada tokoh masyarakat dan orang-orang awam: Aku tahu apa yang dapat memperbaiki kalian, tetapi aku tidak mau memperbaiki kalian dengan merusak diriku sendiri).

${ }^{42}$ Lihat ibid., h. 516.

${ }^{43}$ Lihat ibid.

${ }^{44}$ Pada suatu hari datang kepadanya dua orang wanita minta bantuan. Kepadanya berdua menerangkan kehidupannya yang miskin. Setelah yakin bahwa kedua 
Muhammad Patri Arifin, Karakteristik Dakwah Khulafaurrasyidin

Sedangkan dalam aspek politik, Ali sangat tegas dalam melakukan kebijaksanaan pengawasan terhadap para pejabatnya (penguasa daerah). ${ }^{45}$ Dengan tegas ia menuntut tanggung jawab mereka atas penggunaan dana kekayaan negara. Ia pun tegas memerintahkan mereka memenuhi hak kaum muslimin secara adil dalam membagikan ganimah. Ia menginstruksikan kepada para pejabat yang diangkat harus mengucapkan janji di depan rakyat. Apabila rakyat mengakui janjinya itu, maka janji itu mengikat mereka. Baik rakyat maupun pejabat yang bersangkutan tidak boleh menyimpang dari perjanjian itu atau menafsirkannya menurut kemauan sendiri dan pejabat yang bersangkutanlah yang menetapkan hukumannya. Dan apabila pejabat yang bersangkutan menyimpang, ia pun harus dikenakan hukuman dan khalifahlah yang menetapkan hukumannya. ${ }^{46}$

Lebih dari itu Ali juga mengirimkan pengawas yang bertugas menyelidiki tingkah laku pejabat daerah. Mereka wajib melaporkan semestinya kepada khalifah. Beberapa orang di antara pengawas itu sengaja dirahasiakan. Ali juga menetapkan, setiap penduduk setempat harus mengawasi penguasanya. Setiap orang mempunyai hak penuh

orang itu memang perlu dibantu, ia menyuruh seseorang untuk membeli pakaian dan makanan untuk keduanya, di samping sejumlah uang, tetapi salah seorang diantara dua wanita itu minta agar diistimewakan lebih dari pada temannya, lantaran ia merasa dirinya seorang wanita Arab sedangkan temannya adalah seorang wanita mawaliy (bekas tawanan perang). Sebelum menjawab, Ali mengambil segenggam tanah, kemudian sambil mengamat-amatinya, ia berkata: yang kuketahui ialah bahwa lebih mengutamakan seseorang di atas yang lain karena taat dan taqwanya. Lihat $i b i d$.

${ }^{45}$ Kebijakan Ali terhadap penguasa daerah tidak menyimpang sedikitpun dari kebijaksanaan Umar, kebijaksanaan itu telah dirintis oleh Nabi dan ditegakkan oleh Abu Bakar dan Umar, Ali hanya menghidupkannya kembali, setelah pada tahun-tahun terakhir kekhalifahan Utsman kurang diperhatikan.

${ }^{46}$ Lihat ibid., h. 518. 


\section{$\Delta$-nis $3 \exists \bar{\lambda} /$, Volume 13 Nomor 1, Januari-Juni 2017: 165-182}

menyampaikan pengaduan kepada khalifah mengenai penyelewengan yang dilakukan oleh pejabat daerah. ${ }^{47}$ Demikianlah Ali dengan segala potensi yang dimilikinya menunjukkan betapa perhatian dan upaya dakwah yang dilakukannya demikian beragam dan relevan, yang meliputi aspek ritual, sosial,keadilan, politik, perdagangan dan sebagainya, sehingga tergambar sistemik, strategis dan efektif.

\section{Penutup}

Sebagai khalifah Rasulullah, Abu Bakar menaruh perhatian khusus pada penyebaran jalan hidup yang benar. Karena usahanya seluruh Arab sekali lagi dan untuk selamanya masuk kembali ke dalam Islam. Umar sebagai wakil dari Rasulullah saw. tugas terpentingnya adalah menyebarkan dan mengajarkan Islam. Tujuan utama dari pertempuran dan perjuangan adalah membersihkan jalan bagi kaum muslim untuk mengajarkan Islam. Kapan saja suatu pasukan perang menyerang suatu tempat tertentu harus menyeru penduduk setempat kepada Islam. Umar r.a sangat tegas dalam hal ini dan telah memberikan pesan tetap kepada para komandan untuk tidak memulai perang kecuali mereka pertamatama telah mengajak orang-orang kepada Islam.

Usman menghabiskan banyak waktunya dalam pengajaran kepada para tawanan perang. Banyak di antara mereka menerima Islam karena usahanya. Ia juga mengajar hukum Islam kepada kaum muslimin. 'Ali menganggap bahwa penyebaran dan pengajaran cara hidup yang benar yakni Islam, adalah satu di antara tugas-tugas terpenting seorang khalifah.

\footnotetext{
${ }^{47}$ Lihat ibid.
} 
Muhammad Patri Arifin, Karakteristik Dakwah Khulafaurrasyidin

\section{Daftar Pustaka}

Arnold, Thomas W. The Preaching of Islam. Cet. IV; Lahore Ashraf Printing Press, 1979.

Baidai, Hasan. Kunci Sukses Petugas Dakwah. Cet. I; Yogyakarta: Bina Usaha, 1984.

Bek, Al-Khudariy. Tarikh Tasyri' al-Islamiy. Mesir: Daar al-Fikr, 1968.

Depdikbud. Kamus Besar Bahasa Indonesia. Cet. II; Jakarta: Balai Pustaka, 1989.

Djunaidi, Mahbub. Seratus Tokoh yang Paling Berpengaruh dalam Sejarah. Cet. I; Jakarta: Pustaka Jaya, 1982.

Ensiklopedi Islam. Jilid I. Jakarta: Ikhtiar Baru, 1994.

Hafiduddin, Didin. Dakwah Aktual. Cet. I; Jakarta: Gema Insani Press, 1998.

Hassan, Ibrahim Hassan. Islamic History and Culture from 632 - 1968, diterjemahkan oleh Djahdan Human dengan judul Sejarah dan Kebudayaan Islam. Cet. I; Yogyakarta: Kota Kembang, 1990.

Husain, Thaha. al-Fitnah al-Kubra. diterjemahkan oleh Moh. Tohir dengan judul Malapetaka Terbesar dalam Sejarah Islam. Cet. I; Jakarta: Pustaka Jaya, 1985.

Iqbal, Afzal. Diplomasi Islam. Cet. I; Jakarta: Pustaka al-Kautsar, 2000.

Khan, Madjid Ali. Sisi Hidup Para Khalifah Saleh. Cet. I; Surabaya: Risalah Gusti, 2000.

Nadwi, Syah Mu'inuddin. Khulafaur Rasyidin. Cet. III; India: Azangarh, 1994.

Sjadzali, Munawir. Islam dan Tata Negara: Ajaran, Sejarah dan Pemikiran. Edisi V; Jakarta: UI-Press, 1993.

Syalabiy, Ahmad. Mausu'at al-tarikh wa al-Hadarat al-Islamiyyah. Jilid IV Cet.V; Mesir: Maktabah al-Nahdhah al-Misriyyah, 1979.

Al-Tabariy, Tarikh al-Tabariy Juz III; t.tp: al-Ma'arif, t.th.

Zahrah, Abu. Dakwah Islamiyah. Cet. I; Bandung: Remaja Rosdakarya, 1994.

-------. Khatam al-Nabiyyin. Cet. I; t.tp.: Maktabah Fikriyah, t.th. 